\title{
Thyroid-stimulating Hormone and Insulin Resistance: Their Association with Polycystic Ovary Syndrome without Overt Hypothyroidism
}

\section{Hormônio tireoestimulante e resistência insulínica: sua associação com a síndrome do ovário policístico sem hipotireoidismo clínico}

\author{
Cristina Laguna Benetti-Pinto ${ }^{1}$ Vanessa Berini Piccolo ${ }^{1}$ Daniela Angerame Yela ${ }^{1}$ Heraldo Garmes ${ }^{2}$ \\ ${ }^{1}$ Department of Obstetrics and Gynecology, Faculdade de Medicina \\ da Universidade Estadual de Campinas (UNICAMP), Campinas, SP, \\ Brazil \\ 2 Department of Clinics, Faculdade de Medicina da Universidade \\ Estadual de Campinas (UNICAMP), Campinas, SP, Brazil \\ Address for correspondence Cristina Laguna Benetti-Pinto, MD, PhD, \\ Department of Obstetrics and Gynecology, Faculdade de Medicina da \\ Universidade Estadual de Campinas (UNICAMP), Av. Alexander \\ Fleming, 101, Cidade Universitária, 13083-881 Campinas, SP, Brazil \\ (e-mail: laguna.unicamp@gmail.com).
}

Rev Bras Ginecol Obstet 2017;39:224-228.

\begin{abstract}
Keywords

- polycystic ovary syndrome

- thyroid-stimulating hormone

- insulin resistance

- hypothyroidism

- dyslipidemia

Objective This study analyzed the effectiveness of the thyroid-stimulating hormone (TSH) as a predictor of insulin resistance (IR) and its association with the clinical and metabolic parameters of women with polycystic ovary syndrome (PCOS) without overt hypothyroidism.

Study Design A cross-sectional study was performed. Women with PCOS and without overt hypothyroidism $(n=168)$ were included.

Methods Receiver operating characteristic (ROC) curve was used to determine the cut-off point for TSH that would maximize sensitivity and specificity for a diagnosis of IR using homeostatic model assessment of insulin resistance (HOMA-IR) $\geq 2.71$. Clinical and metabolic parameters were compared as a function of the TSH cut-off limit and the presence of IR.

Results Thyroid-stimulating hormone $\geq 2.77 \mathrm{mIU} / \mathrm{L}$ was associated with a diagnosis of IR, with sensitivity of $47.9 \%$ and specificity of $65.3 \%$. There were no differences in clinical, hormonal or metabolic parameters between TSH $<2.77$ and TSH of $2.77-10 \mathrm{mlU} / \mathrm{L}$. Conclusion In women with PCOS without overt hypothyroidism, TSH $\geq 2.77 \mathrm{mIU} / \mathrm{L}$ is associated with IR; however, with poor sensibility, showing TSH to be a poor predictor of $I R$ in this population. No clinical or metabolic alterations were found that would justify a change in clinical management. Thus, the IR should be investigated in all women with PCOS irrespective of TSH level.
\end{abstract}

received

September 4, 2016 accepted after revision January 26, 2017 published online April 11, 2017
DOI https://doi.org/

10.1055/s-0037-1601436. ISSN 0100-7203.
Copyright (e 2017 by Thieme Revinter

Publicações Ltda, Rio de Janeiro, Brazil
License terms

(c) $(1) \$$ 


\section{Resumo}

\section{Palavras-chave}

- síndrome do ovário policístico

- hormônio tireoestimulante

- resistência insulínica

- hipotireoidismo

- dislipidemia
Objetivo Este estudo analisou a efetividade do hormônio tireoestimulante (TSH) como preditor da resistência insulínica (IR), bem como a associação do TSH com os parâmetros clínicos e metabólicos de mulheres com síndrome do ovário policístico (PCOS) sem hipotireoidismo clínico.

Desenho do Estudo Estudo de corte transversal com inclusão de mulheres com PCOS e sem hipotireoidismo clínico $(n=168)$.

Métodos Utilizou-se análise através de curva ROC (Receiver operating characteristic) para determinar o valor de corte para o nível sérico de TSH que poderia maximizar a sensibilidade e especificidade para o diagnóstico de IR considerada com avaliação da homeostase de resistência insulínica (HOMA-IR) $\geq 2.71$. Parâmetros clínicos e metabólicos foram comparados de acordo com o ponto de corte de TSH determinado e com a presença de IR.

Resultados Níveis séricos de TSH $\geq 2.77 \mathrm{mIU} / \mathrm{L}$ estiveram associados com o diagnóstico de IR, com sensibilidade de $47.9 \%$ e especificidade de $65.3 \%$. Não foram evidenciadas diferenças nos parâmetros clínicos, hormonais e metabólicos quando TSH $<2.77$ ou TSH de $2.77-10 \mathrm{mlU} / \mathrm{L}$.

Conclusão Em mulheres com PCOS sem hipotireoidismo, TSH $\geq 2.77 \mathrm{mIU} / \mathrm{L}$ está associado a IR, porém com baixa sensibilidade, mostrando que a dosagem de TSH não é um bom preditor de IR nesta população. Também não se evidenciou alteração clínica ou metabólica que justificasse alteração na investigação desta população. Assim, a resistência insulínica deve ser investigada em todas as mulheres com PCOS, independente dos níveis séricos de TSH.

\section{Introduction}

Polycystic ovary syndrome (PCOS) is an endocrine and metabolic disorder that affects between 5 and $10 \%$ of women of reproductive age. ${ }^{1-3}$ It is already known that around $20-40 \%$ of women with PCOS have insulin resistance (IR) compared with a prevalence of $5-10 \%$ in the general population. In women with PCOS, IR has been associated with an increased risk of the metabolic syndrome, type 2 diabetes mellitus, and cardiovascular disease, and has been reported to cause subfertility. $2,4,5$

The physiopathology of the higher incidence of IR in PCOS, even when compared with the population of the same age and body mass index (BMI), needs to be better clarified. ${ }^{6,7}$ The genetic component in the origin of IR is already wellestablished ${ }^{8}$ however, a multifactorial pathogenesis has been suggested, with effects such as hyperandrogenemia ${ }^{9}$ and others, including thyroid function. ${ }^{7}$

An association has been reported between plasma levels of thyroid-stimulating hormone (TSH) and fasting insulin and insulin sensitivity in the literature. ${ }^{10}$ In women with PCOS, little information is available regarding the relationship between IR and different TSH levels. Mueller et $\mathrm{al}^{7}$ reported that serum TSH levels $\geq 2 \mathrm{mIU} / \mathrm{L}$ showed better sensitivity and specificity for the identification of women with both PCOS and IR. These results have been the subject of much debate and were not always reproducible.

The objective of the present study was to evaluate whether thyroid function is associated with a greater risk of IR by identifying the TSH level that would result in the highest sensitivity and specificity for the presence of IR in women with PCOS and without overt hypothyroidism. Differences in the clinical and laboratory parameters of women with PCOS and TSH levels above and below this cut-off level were also evaluated as a function of the presence or absence of IR.

\section{Subjects and Methods}

\section{Subjects}

A cross-sectional study evaluated 168 women with a diagnosis of PCOS in accordance with the Rotterdam criteria (Rotterdam ESHRE/ASRM 2004), who were receiving care during 12 years as outpatients at the Department of Gynecology and Obstetrics, Faculdade de Medicina da Universidade Estadual de Campinas (UNICAMP). The study was approved by the Institution's Internal Review Board.

The women were included in the study at the time of diagnosis, that is, prior to the initiation of any hormonal or hypoglycemic drugs. We have only included women without necessity of thyroid hormone replacement (TSH $\leq 10$ and normal levels of free T4, without clinical symptoms). Patients with chronic diseases, such as overt hypothyroidism or hyperthyroidism, kidney or liver failure, hyperprolactinemia, late onset adrenal hyperplasia and diabetes were excluded from the study.

\section{Methods}

Anthropometric data (weight, height, waist and hip circumference) were collected, blood pressure was measured, and a clinical evaluation of the androgenic manifestations was 
performed. Body mass index was calculated from the ratio between the women's weight and square height, expressed as $\mathrm{kg} / \mathrm{m}^{2}$. Hirsutism was classified in accordance with the Ferriman-Gallwey Index.

Thyroid-stimulating hormone (TSH), free T4 (FT4), free testosterone, total testosterone, dehydroepiandrosterone sulfate (DHEAS), prolactin (PRL), fasting glucose, fasting insulin, triglycerides, total cholesterol, high-density lipoprotein cholesterol (HDL-C) and low-density lipoprotein cholesterol (LDL-C) levels were measured. The blood samples were obtained from peripheral veins between the $3^{\text {rd }}$ and $9^{\text {th }}$ days of the menstrual cycle, or 60 days after the last menstrual period, following a fasting period of at least 12 hours.

Glucose levels were measured using an enzymatic colorimetric method (Roche/Hitachi 904/911 Modular ACN 249, Indianapolis, USA). Insulin was measured using a chemiluminescent immunometric method (Immulite/Immulite 1000, Siemens, Los Angeles, USA).

Total cholesterol, HDL cholesterol, LDL cholesterol and triglycerides were analyzed using an enzymatic colorimetric test (Roche/Hitachi Modular ACN, Indianapolis, USA).

Dehydroepiandrosterone sulfate was measured using a chemiluminescent immunometric method (Immulite/Immulite 1000 DHEA-S04, Llanberis, UK). Thyroid-stimulating hormone, FT4, prolactin and total testosterone levels were measured by electrochemiluminescence (Cobas e411, Mannheim, Germany). Free testosterone was measured by radioimmunoassay (Beckman Coulter DSL 4900, Prague, Czech Republic).

Insulin resistance was also evaluated using the homeostatic model assessment of insulin resistance (HOMA-IR), which represents an indirect evaluation of IR made by measuring endogenous insulin and glucose after a 12-hour fasting period. Homeostatic model assessment of insulin resistance $\geq 2.71$, the cut-off point established for a diagnosis of IR in the Brazilian population, was defined as the cut-off point for the present study. ${ }^{11}$

\section{Statistical Analysis}

Sample size was based on the sensitivity of the cut-off point for TSH. Recent studies indicated sensitivity of around $60 \%{ }^{7}$ Considering a prevalence of IR of $50 \%^{4}$ in the sample, with sensitivity and specificity of $60 \%, 10 \%$ sampling error and significance of $5 \%$ (expected confidence interval for sensitivity/specificity: 50-70\%), according to the calculation proposed by Flahault et al, ${ }^{12}$ the total sample would have to consist of at least 134 cases.

To determine the cut-off point for TSH that would maximize sensitivity and specificity for a diagnosis of IR, the receiver operating characteristics (ROC) curve methodology was used for TSH levels, considering IR as the gold standard.

Once the cut-off point was established by the ROC curve, the Student $t$-test and the Mann-Whitney test were used to evaluate the independent variables in accordance with this cut-off classification of TSH and also as a function of whether IR was present or not.

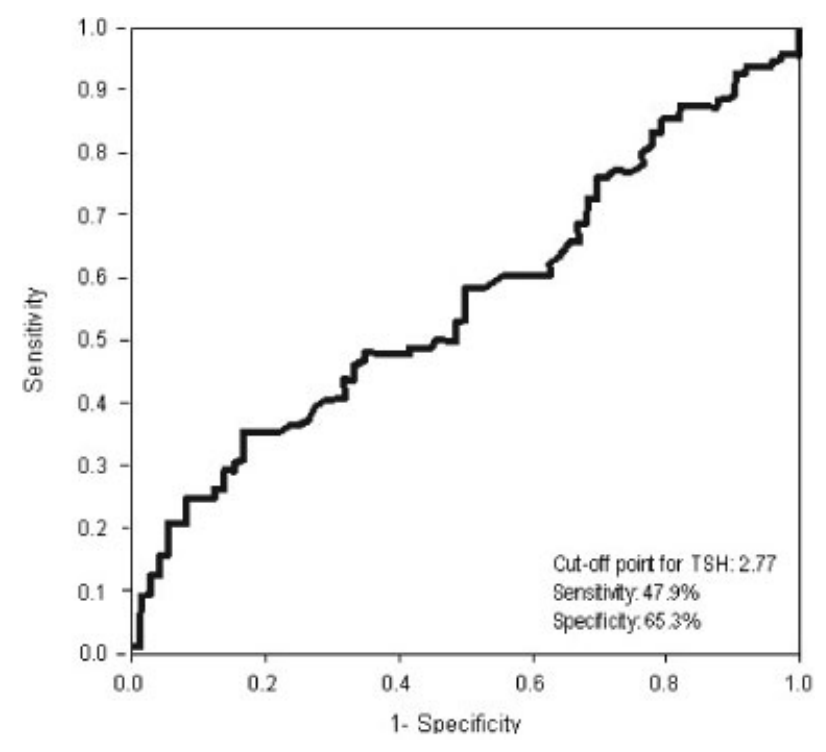

Fig. 1 Receiver operating characteristic curve to evaluate the association between TSH and IR, measured according to HOMA-IR, in women with PCOS $(n=168)$.

Significance level was defined at $5 \%$ and the software used throughout the analysis was the SAS statistical software package, version 9.1 (Cary, NC, USA).

\section{Results}

The mean age of the 168 women with PCOS was $24.2 \pm 5.8$ years. Mean body mass index was $33.45 \pm 8.23 \mathrm{~kg} / \mathrm{m}^{2}$. The mean Ferriman-Gallwey score was $12.05 \pm 4.37$. Mean serum TSH level was $2.71 \pm 1.57 \mathrm{mIU} / \mathrm{L}$ and mean HOMA-IR was $3.63 \pm 2.75$.

The association between TSH and IR, evaluated using the ROC curve, showed a cut-off value for TSH of $2.77 \mathrm{mIU} / \mathrm{L}$, with sensitivity of $47.9 \%$ and specificity of $65.3 \%$ (area under the ROC curve $=0.5642$ ) for a diagnosis of IR ( - Fig. 1).

The clinical, hormonal and metabolic parameters were compared in accordance with the cut-off point established by the ROC curve for two groups: Thyroid-stimulating hormone levels $<2.77 \mathrm{mIU} / \mathrm{L}$ and TSH levels of 2.77 to $10 \mathrm{mIU} / \mathrm{L}$. In 97 women, serum TSH levels were $<2.77 \mathrm{mIU} / \mathrm{L}$, while in 71 women levels were $\geq 2.77 \mathrm{mIU} / \mathrm{L}$. No statistically significant difference was found in the clinical, hormonal or metabolic parameters between the women with TSH levels below the established cut-off limit and those with levels above this limit, except for FT4, which was higher in the group with $\mathrm{TSH} \geq 2.77 \mathrm{mIU} / \mathrm{L}(p=0.005)$ (-Table 1$)$.

\section{Discussion}

This study showed that, despite of TSH levels $\geq 2.77 \mathrm{mIU} / \mathrm{L}$ being associated with IR, serum TSH level is not a good predictor of IR in young women with PCOS without overt hypothyroidism. The clinic, hormonal and metabolic parameters evaluated did not differ as a function of the defined cutoff value. 
Table 1 Comparison of the clinical, hormonal and metabolic parameters of women with PCOS according to serum TSH level $<2.77$ or $\geq 2.77 \mathrm{mlU} / \mathrm{L}$

\begin{tabular}{|l|l|l|l|}
\hline Variables & $\begin{array}{l}\text { TSH }<2.77 \\
(\boldsymbol{n}=\mathbf{9 7})\end{array}$ & $\begin{array}{l}\text { TSH } \geq 2.77 \mathrm{mIU} / \mathrm{L} \\
(\boldsymbol{n}=\mathbf{7 1})\end{array}$ & $\boldsymbol{p}$ \\
\hline Age $($ years $)$ & $24.67 \pm 6.01$ & $23.58 \pm 5.48$ & 0.2158 \\
\hline BMI $\left(\mathrm{kg} / \mathrm{m}^{2}\right)$ & $32.98 \pm 7.1$ & $34.04 \pm 9.48$ & 0.6193 \\
\hline Ferriman-Gallwey score & $12.16 \pm 4.47$ & $11.86 \pm 4.24$ & 0.7402 \\
\hline SBP $(\mathrm{mmHg})$ & $116.06 \pm 13.85$ & $116.18 \pm 15.07$ & 0.9542 \\
\hline DBP $(\mathrm{mmHg})$ & $74.04 \pm 9.31$ & $73.24 \pm 9.53$ & 0.8270 \\
\hline WC $(\mathrm{cm})$ & $99.74 \pm 12.99$ & $102.55 \pm 18.02$ & $0.5508^{*}$ \\
\hline HC $(\mathrm{cm})$ & $116.52 \pm 11.76$ & $114.72 \pm 11.74$ & 0.8226 \\
\hline TT $(\mathrm{ng} / \mathrm{mL})$ & $0.72 \pm 0.38$ & $2.41 \pm 12.26$ & 0.8536 \\
\hline FT $(\mathrm{pg} / \mathrm{mL})$ & $2.52 \pm 1.33$ & $2.64 \pm 1.45$ & 0.6395 \\
\hline FT4 $(\mathrm{ng} / \mathrm{dL})$ & $1.17 \pm 0.17$ & $1.26 \pm 0.21$ & $0.0051^{*}$ \\
\hline PRL $(\mathrm{ng} / \mathrm{mL})$ & $14.56 \pm 12.17$ & $14.34 \pm 6.56$ & 0.3425 \\
\hline DHEAS $(\mu \mathrm{dg} / \mathrm{dL})$ & $178.77 \pm 92.73$ & $199.16 \pm 134.10$ & 0.7251 \\
\hline GLU $(\mathrm{mg} / \mathrm{dL})$ & $87.49 \pm 12.98$ & $87.63 \pm 15.54$ & 0.7642 \\
\hline INSUL $(\mu \mathrm{lU} / \mathrm{mL})$ & $16.20 \pm 11.19$ & $16.49 \pm 10.33$ & 0.7064 \\
\hline HOMA-IR & $3.64 \pm 2.99$ & $3.62 \pm 2.42$ & 0.6687 \\
\hline CHOL $(\mathrm{mg} / \mathrm{dL})$ & $178.96 \pm 36.00$ & $187.86 \pm 37.81$ & $0.1949^{*}$ \\
\hline HDL-C $(\mathrm{mg} / \mathrm{dL})$ & $46.44 \pm 12.56$ & $47.20 \pm 15.38$ & 0.7281 \\
\hline LDL-C $(\mathrm{mg} / \mathrm{dL})$ & $102.89 \pm 30.24$ & $114.05 \pm 34.85$ & 0.0718 \\
\hline TRIG $(\mathrm{mg} / \mathrm{dL})$ & $144.02 \pm 94.65$ & $143.12 \pm 73.71$ & 0.5232 \\
\hline
\end{tabular}

Variables are expressed as means \pm standard deviations.

${ }^{*}$ Student $t$-test. All other variables were evaluated using the Mann-Whitney test.

Abbreviations: BMI, body mass index; CHOL, cholesterol; DBP, diastolic blood pressure; DHEAS, dehydroepiandrosterone sulfate; FT, free testosterone; FT4, free T4; GLU, glucose; HC, hip circumference; HDL-C, high-density lipoprotein cholesterol; HOMA-IR, homeostatic model assessment of insulin resistance; INSUL, insulin; LDL-C, low-density lipoprotein cholesterol; PCOS, polycystic ovary syndrome, PRL, prolactin; SBP, systolic blood pressure;TRIG, triglycerides; TSH, thyroid stimulating hormone; TT, total testosterone; WC, waist circumference.

Polycystic ovary syndrome is increasingly viewed as a metabolic disease, with important alterations in insulin levels, generating clinical consequences and high morbidity throughout life. Hypothyroidism has been shown to cause many metabolic derangements. In particular, it has been extensively demonstrated that thyroid hormones have insulin antagonistic effects at the liver level that lead to an increased glucose hepatic output, via an enhanced rate of gluconeogenesis and glycogenolysis. ${ }^{13}$ For this reason, all the existing criteria used for the diagnosis of PCOS necessitate exclusion of hypothyroidism at first. ${ }^{14}$ Studied previously performed by us and other authors showed that the prevalence of subclinical hypothyroidism $(\mathrm{SCH})$ is increased in women with $\mathrm{PCOS}$, and $\mathrm{SCH}$ is associated with metabolic imbalances. ${ }^{15,16}$ Regarding the literature, even in the absence of symptoms, replacement therapy with L-thyroxine is recommended for younger patients with serum TSH $>10 \mathrm{mIU} / \mathrm{L} .{ }^{17}$ However, the association between glucose metabolism, insulin and thyroid function in women with PCOS and without overt hypothyroidism remains to be fully clarified. To assess this association, young women with PCOS and TSH levels of up to $10 \mathrm{mIU} / \mathrm{L}$, and normal free T4 levels were evaluated in this study.
In the present study, the TSH value of $2.77 \mathrm{mIU} / \mathrm{L}$ was found to offer the best specificity and sensitivity for a diagnosis of IR in a population of young women with PCOS. Other studies have shown an association of IR with TSH values of $2.0 \mathrm{mIU} / \mathrm{L}^{7}$ and $2.5 \mathrm{mIU} / \mathrm{L},{ }^{18}$ both very close to the value obtained in the present study. In the research by Mueller et al, ${ }^{7}$ IR was more common in women with PCOS and TSH $>2$ than those with TSH $<2$. In another study, the same group showed that BMI, IR indexes and total and free testosterone levels were higher in women with PCOS and TSH levels $>2.5 \mathrm{mIU} / \mathrm{L}$ compared with those with lower TSH levels. ${ }^{18}$

Our results were different, and they don't confirm this question. When the clinical and laboratory parameters of women with PCOS were compared for TSH levels $<$ or $\geq$ than the cut-off point of 2.77 up to a limit of $10 \mathrm{mIU} / \mathrm{L}$, no differences were found in the clinical or hormonal manifestations or in metabolic parameters. So, the present findings fail to supply any evidence in support of changing diagnostic management or even therapeutic management in women with PCOS without overt hypothyroidism as a function of the association of IR and normal TSH levels. In agreement with 
some of the present results, Ganie et al ${ }^{19}$ compared the same parameters in relation to several TSH levels and found differences only in total cholesterol and triglyceride levels with TSH levels $>3 \mathrm{mIU} / \mathrm{L}$ and $>4 \mathrm{mIU} / \mathrm{L}$, respectively. They found no statistically significant differences in the other anthropometric and clinical parameters or with respect to the great majority of the laboratory parameters in the women with PCOS and normal thyroid function. In the same direction, Enzevaei et $\mathrm{al}^{20}$ did not find a relationship between SCH and IR in women with PCOS.

A strong point of our study was the significant and homogeneous sample of women with PCOS without overt hypothyroidism included, but we need to reinforce that this was a cross-sectional study, like the majority of other researches with the same aim in the literature. Considering the variability of results in the literature about the influence of $\mathrm{SCH}$ on the metabolic profile of PCOS, a recent meta-analysis $^{21}$ that included one study from our group, ${ }^{15}$ concluded that there is no direct evidence to support that $\mathrm{SCH}$ exerts a detrimental impact on the metabolic and hormonal profile of patients with PCOS. So, the discussion could be still: can the TSH levels change the investigation of IR in women with PCOS and without overt hypothyroidism?

In this study, a large number of women were evaluated, and a cut-off value of $2.77 \mathrm{mIU} / \mathrm{L}$ for TSH was established, which was expected to indicate a higher prevalence of IR. However, this diagnostic model was found to have poor sensitivity, and failed to provide any evidence that would justify changes in the investigation of women with PCOS. Therefore, our conclusion is that the presence of IR should be investigated in all women with PCOS, irrespective of thyroid function.

\section{References}

1 Adams J, Polson DW, Franks S. Prevalence of polycystic ovaries in women with anovulation and idiopathic hirsutism. Br Med J (Clin Res Ed) 1986;293(6543):355-359

2 Azziz R, Sanchez LA, Knochenhauer ES, et al. Androgen excess in women: experience with over 1000 consecutive patients. J Clin Endocrinol Metab 2004;89(02):453-462

3 Azziz R, Carmina E, Dewailly D, et al; Androgen Excess Society. Positions statement: criteria for defining polycystic ovary syndrome as a predominantly hyperandrogenic syndrome: an Androgen Excess Society guideline. J Clin Endocrinol Metab 2006; 91(11):4237-4245

4 Dunaif A. Insulin resistance and the polycystic ovary syndrome: mechanism and implications for pathogenesis. Endocr Rev 1997; 18(06):774-800

5 Lois K, Valsamakis G, Mastorakos G, Kumar S. The impact of insulin resistance on woman's health and potential treatment options. Ann N Y Acad Sci 2010;1205:156-165
6 Barber TM, McCarthy MI, Wass JA, Franks S. Obesity and polycystic ovary syndrome. Clin Endocrinol (Oxf) 2006;65(02): 137-145

7 Mueller A, Schöfl C, Dittrich R, et al. Thyroid-stimulating hormone is associated with insulin resistance independently of body mass index and age in women with polycystic ovary syndrome. Hum Reprod 2009;24(11):2924-2930

8 Diamanti-Kandarakis E, Alexandraki K, Bergiele A, Kandarakis H, Mastorakos G, Aessopos A. Presence of metabolic risk factors in non-obese PCOS sisters: evidence of heritability of insulin resistance. J Endocrinol Invest 2004;27(10):931-936

9 Möhlig M, Jürgens A, Spranger J, et al. The androgen receptor CAG repeat modifies the impact of testosterone on insulin resistance in women with polycystic ovary syndrome. Eur J Endocrinol 2006; 155(01):127-130

10 Chubb SA, Davis WA, Davis TM. Interactions among thyroid function, insulin sensitivity, and serum lipid concentrations: the Fremantle diabetes study. J Clin Endocrinol Metab 2005; 90(09):5317-5320

11 Geloneze B, Tambascia MA. [Laboratorial evaluation and diagnosis of insulin resistance]. Arq Bras Endocrinol Metabol 2006; 50(02):208-215

12 Flahault A, Cadilhac M, Thomas G. Sample size calculation should be performed for design accuracy in diagnostic test studies. J Clin Epidemiol 2005;58(08):859-862

13 Nada AM. Effect of treatment of overt hypothyroidism on insulin resistance. World J Diabetes 2013;4(04):157-161

14 Ciaraldi TP, Aroda V, Mudaliar S, Chang RJ, Henry RR. Polycystic ovary syndrome is associated with tissue-specific differences in insulin resistance. J Clin Endocrinol Metab 2009;94(01):157-163

15 Benetti-Pinto CL, Berini Piccolo VR, Garmes HM, Teatin Juliato CR. Subclinical hypothyroidism in young women with polycystic ovary syndrome: an analysis of clinical, hormonal, and metabolic parameters. Fertil Steril 2013;99(02):588-592

16 Tagliaferri V, Romualdi D, Guido M, et al. The link between metabolic features and TSH levels in polycystic ovary syndrome is modulated by the body weight: an euglycaemic-hyperinsulinaemic clamp study. Eur J Endocrinol 2016;175(05):433-441

17 Pearce SHS, Brabant G, Duntas LH, et al. 2013 ETA Guideline: management of subclinical hypothyroidism. Eur Thyroid J 2013; 2(04):215-228

18 Dittrich R, Kajaia N, Cupisti S, Hoffmann I, Beckmann MW, Mueller A. Association of thyroid-stimulating hormone with insulin resistance and androgen parameters in women with PCOS. Reprod Biomed Online 2009;19(03):319-325

19 Ganie MA, Laway BA, Wani TA, et al. Association of subclinical hypothyroidism and phenotype, insulin resistance, and lipid parameters in young women with polycystic ovary syndrome. Fertil Steril 2011;95(06):2039-2043

20 Enzevaei A, Salehpour S, Tohidi M, Saharkhiz N. Subclinical hypothyroidism and insulin resistance in polycystic ovary syndrome: is there a relationship? Iran J Reprod Med 2014;12(07): 481-486

21 Pergialiotis V, Konstantopoulos P, Prodromidou A, Florou V, Papantoniou N, Perrea DN. MANAGEMENT OF ENDOCRINE DISEASE: The impact of subclinical hypothyroidism on anthropometric characteristics, lipid, glucose and hormonal profile of PCOS patients: a systematic review and meta-analysis. Eur J Endocrinol 2017;176(03):R159-R166 